\title{
O hábito de tomar banho: a aplicação de Sondas Culturais para coleta de dados privados
}

\section{The habit of bathing: the application of cultural probes in private data collection}

\author{
Aline Müller Garcia, Universidade Federal do Paraná - UFPR. \\ eilan.muller@gmail.com \\ Aguinaldo dos Santos, Universidade Federal do Paraná - UFPR. \\ asantos@ufpr.br
}

\begin{abstract}
Resumo
Em pesquisas que seguem os preceitos do Design Centrado no Usuário com temas relacionados às rotinas domésticas, é comum que em algumas situações a intimidade dos participantes seja uma barreira para a coleta dos dados. Este artigo apresenta o relato de uma etapa de pesquisa sobre hábitos de banho, no qual aplicamos sondas culturais como ferramentas para coleta de dados sem a necessidade da presença do pesquisador. Com a aplicação das sondas culturais foi possível obter dados qualitativos que os usuários muitas vezes têm dificuldade em verbalizar em uma entrevista ou outro meio convencional. Os dados identificados com as sondas culturais foram analisados individualmente e possibilitaram a identificação de requisitos para projetos de design que não seriam levados em consideração sem a aplicação destas ferramentas. Assim, apresentamos a utilização das sondas culturais e destacamos o seu potencial de contribuição com estudos que envolvem a privacidade e a intimidade dos participantes.
\end{abstract}

Palavras-chave: Sondas culturais, Banho, Intimidade.

\begin{abstract}
In researches that follow the precepts of User Centered Design with themes related to domestic routines, it is common for intimacy to be a barrier in some situations. This article presents the report of a stage of a study about bathing habits, in which we apply cultural probes as data collection tools with no need for the presence of the researcher with the user. It was possible to obtain, with the application of cultural probes, qualitative data that is sometimes difficult for users to verbalize in an interview or other conventional way. The samples of data identified with the cultural probes were analyzed individually and contributed to the identification of requirements for design projects that would not be considered without the application of these tools. Thereby, we present the use of cultural probes and highlight their potential to contribute to studies that involve participants' privacy and intimacy.
\end{abstract}

Keywords: Cultural Probes, Bath, Intimacy. 


\section{Introdução}

Este artigo descreve uma etapa de pesquisa da dissertação de mestrado de Garcia (2019), cujo objetivo foi compreender e caracterizar o hábito de tomar banho. Por meio da compreensão profunda dos padrões de comportamento que as pessoas adotam durante suas práticas de banho foi possível o desenvolvimento de soluções que contribuam para o controle do consumo de água e energia. Os participantes da pesquisa foram representantes de famílias de baixa renda residentes na região metropolitana de Curitiba-PR. Com a pesquisa também foi possível identificar as necessidades dos usuários, para assim extrair requisitos de projetos de design relacionados ao banho. $\mathrm{O}$ objetivo da pesquisa foi encontrar soluções que beneficiem usuários de baixa renda, possibilitando a economia de água e energia e, ao mesmo tempo, orientar empresas que produzem produtos e/ou serviços sobre as necessidades e desejos destes usuários. Para atingir tais objetivos acompanhamos os hábitos de seis famílias residentes em HIS (habitação de interesse social), nas quais as mulheres, mães e avós, foram as principais interlocutoras. Ao planejar os procedimentos de coleta de dados da pesquisa nos deparamos com a seguinte questão: como acompanhar um hábito tão íntimo e particular -como é o caso do banho- sem causar constrangimentos aos participantes?

Estudos que envolvem o desenvolvimento de produtos e serviços relacionados a hábitos íntimos tem sido um desafio para pesquisadores que estudam a vida cotidiana e os ambientes domésticos. Diferente do que ocorre com atividades de trabalho ou lazer, não existe um consenso sobre como fazer pesquisas em contextos de intimidade, especialmente em relação às pesquisas em design, que procuram desenvolver novos artefatos e tecnologias (KJELDSKOV et al, 2004).

As sondas culturais são ferramentas de coleta de dados geralmente aplicadas em estudos que envolvem o Design Centrado no Usuário. Tais ferramentas convidam os usuários a refletir e expressar suas experiências, sentimentos e atitudes e, neste processo, fornecem insights e inspiração para os designers que as aplicam (SANDERS, STAPPERS, 2014). Elas são utilizadas principalmente nos casos em que o pesquisador, por algum motivo, não pode estar presente no momento da coleta de dados. Com estas ferramentas o próprio participante pode realizar a coleta dos seus próprios dados, o que permite uma compreensão maior da sua visão dos fatos e pode torná-lo um coautor da pesquisa (MATTELMÄKI, 2006).

Em sua pesquisa, Kjeldskov et al (2004) utilizam as sondas culturais para explorar a intimidade e as relações de afeto mediadas por tecnologias interativas. Os pesquisadores aplicaram estas ferramentas para compreender como os afetos podem ser mediados por dispositivos e tecnologias interativas. Não foram identificadas na literatura outras pesquisas que evidenciem a utilização das sondas culturais para coletar dados privados dos usuários.

Tomar banho é um dos hábitos mais íntimos na vida cotidiana e encontrar uma forma de mapeá-lo tornou-se um desafio metodológico. Para atender tal situação e adentrar na intimidade 
dos participantes sem causar constrangimentos, desenvolvemos sondas culturais específicas para uma interação no ambiente do banheiro. Assim, neste artigo relatamos as experiências da utilização destas ferramentas no caso desta pesquisa.

Com uma abordagem empática, as participantes desta pesquisa foram convidadas a colaborar com o projeto. Desde o início a pesquisa foi apresentada como um processo de identificação de necessidades e demandas destas mulheres e de suas famílias, nos assuntos relacionados ao banho e a eficientização do uso da água e da energia. Sendo assuntos do cotidiano e de pleno conhecimento das participantes, o convite à contribuição com a coleta de dados criou uma atmosfera de comprometimento e colaboração, que foi essencial para alcançar os resultados que buscamos. Durante toda a pesquisa as participantes tiveram papel ativo, dando suas opiniões sobre produtos e serviços que achavam que deveriam ser criados ou melhorados para atender demandas do banho delas próprias e de suas famílias. Estas participantes também recomendaram outras mulheres dentro do perfil determinado para colaborar com a pesquisa, pois estavam cientes de todas as especificações definidas no projeto desde o início.

Assim, o objetivo deste artigo é descrever a utilização das sondas culturais em uma pesquisa de campo na qual os pesquisadores não podiam ultrapassar os limites da intimidade dos usuários. Também procuramos responder a algumas perguntas-chave como: quais tipos de dados podem ser obtidos com a aplicação de sondas culturais? Como estes dados podem ser analisados e transformados em requisitos de projeto? O que a utilização de sondas culturais agregou à pesquisa desenvolvida?

\section{O hábito de tomar banho: relato da pesquisa de campo}

A estratégia que utilizamos para compreender os hábitos dos participantes e, posteriormente, identificar requisitos de projeto, foi uma pesquisa de campo com abordagem etnográfica. É importante diferenciar a pesquisa aplicada no design da pesquisa etnográfica ou etnografia. A etnografia é um método vindo da antropologia, onde o objetivo é caracterizar hábitos humanos e descrever culturas. Enquanto isso, no design, os estudos com abordagens etnográficas buscam obter informações suficientes para a compreensão de particularidades que correspondem ao foco da pesquisa. Assim, pesquisas de campo com estas abordagens podem ser aplicadas nos estudos em design para compreender a rotina dos usuários, suas experiências com os produtos e serviços, o contexto social e emocional e até mesmo barreiras para mudanças de comportamento e estilos de vidas (O'GRADY, 2017, SANTOS et al., 2018). Nesta pesquisa buscamos compreender e caracterizar o banho através de uma abordagem centrada nos usuários, procurando sempre evidenciar a sua perspectiva e versão dos fatos.

O objetivo deste estudo foi compreender de forma empírica como os participantes tomam banho e também quais hábitos relacionados à atividade contribuem para um maior ou menor consumo de água e energia. A partir desta compreensão foram identificados requisitos projetuais para produtos e serviços de diferentes categorias relacionadas ao banho, desde o ambiente do banheiro, tipos de chuveiro e até mesmo produtos para higiene pessoal. 
A aplicação das sondas culturais corresponde a uma das etapas da pesquisa de campo aplicada que descrevemos neste artigo. Para possibilitar a realização da pesquisa de campo houveram alguns procedimentos importantes em relação a definição do perfil do público que participou da pesquisa assim com a elaboração das ferramentas de coleta de dados. Além das sondas culturais também foram aplicadas entrevistas narrativas e card sortings durante a etapa da pesquisa de campo com os usuários.

\section{Sobre o desenvolvimento e aplicação das ferramentas de coleta de dados}

$\mathrm{Na}$ pesquisa relatada, as entrevistas narrativas abriram os procedimentos de coleta de dados em campo, estimulando os participantes a refletir sobre as especificidades de seu banho. Assim, durante o tempo em que permaneceram com as sondas culturais, os participantes estavam mais atentos para prestar atenção no hábito, que por sua natureza cotidiana e rotineira, muitas vezes se torna menos consciente.

As entrevistas narrativas consistem em uma forma não estruturada de realizar entrevistas. $\mathrm{O}$ objetivo é estimular o entrevistado a contar histórias e conversar de forma mais livre, em caráter de diálogo, a partir do assunto proposto pelo pesquisador. Também são envolvidos neste processo da entrevista características paralinguísticas como tom de voz, entonação, pausas e outros artifícios verbais (MUYLAERT et al, 2014). As entrevistas narrativas consistem em uma alternativa que busca romper com a rigidez das entrevistas estruturadas e/ou semiestruturadas, tendo por objetivo identificar estruturas sociais que moldam as experiências. Narrar um acontecimento ou uma história é uma característica social humana que pode contribuir na identificação de fatores subjetivos que formam trajetórias (MOURA, NACARATO, 2017).

Após a entrevista, aplicamos um card sorting com as usuárias, com o objetivo de avaliar as preferências simbólicas em relação aos artefatos para o banho. $\mathrm{O}$ card sorting ou arranjo de cartas é uma técnica que consiste na apresentação de cartões com informações referentes ao tópico tratado aos participantes, que devem agrupar estas cartas em determinada lógica semântica (PADOVANI, RIBEIRO, 2013). O card sorting é uma ferramenta utilizada para facilitar a conversa contribuindo para evidenciar o que é mais importante para cada pessoa. Com esta ferramenta é possível compreender o que cada usuário pensa e quais são as suas prioridades em relação ao tópico analisado. A ferramenta também possibilita uma abordagem empática, de média dificuldade, que aproxima o pesquisador do contexto de vida dos usuários (CAVALLERO, 2017).

Como terceira técnica de coleta de dados, aplicamos as sondas culturais. As sondas culturais são ferramentas experimentais desenvolvidas nos estudos do Design Centrado no Usuário para compreender fenômenos humanos e assim captar oportunidades para o design. No processo de sondagem os próprios usuários coletam as informações, trabalhando como participantes ativos no processo de design (MATTELMÄKI, 2006). Trata-se de uma coleção de experiências, nas quais os participantes podem expressar seus pensamentos e ideias. As sondas também auxiliam no processo de avaliação e análise das percepções do usuário sobre o tema, tornando assim 
possível compreender valores, hábitos, sentimentos, necessidades, assim como atitudes sociais, estéticas e culturais.

Na Figura 01 é possível visualizar as ferramentas de coleta de dados aplicadas na pesquisa assim como os objetivos da aplicação de cada uma delas.

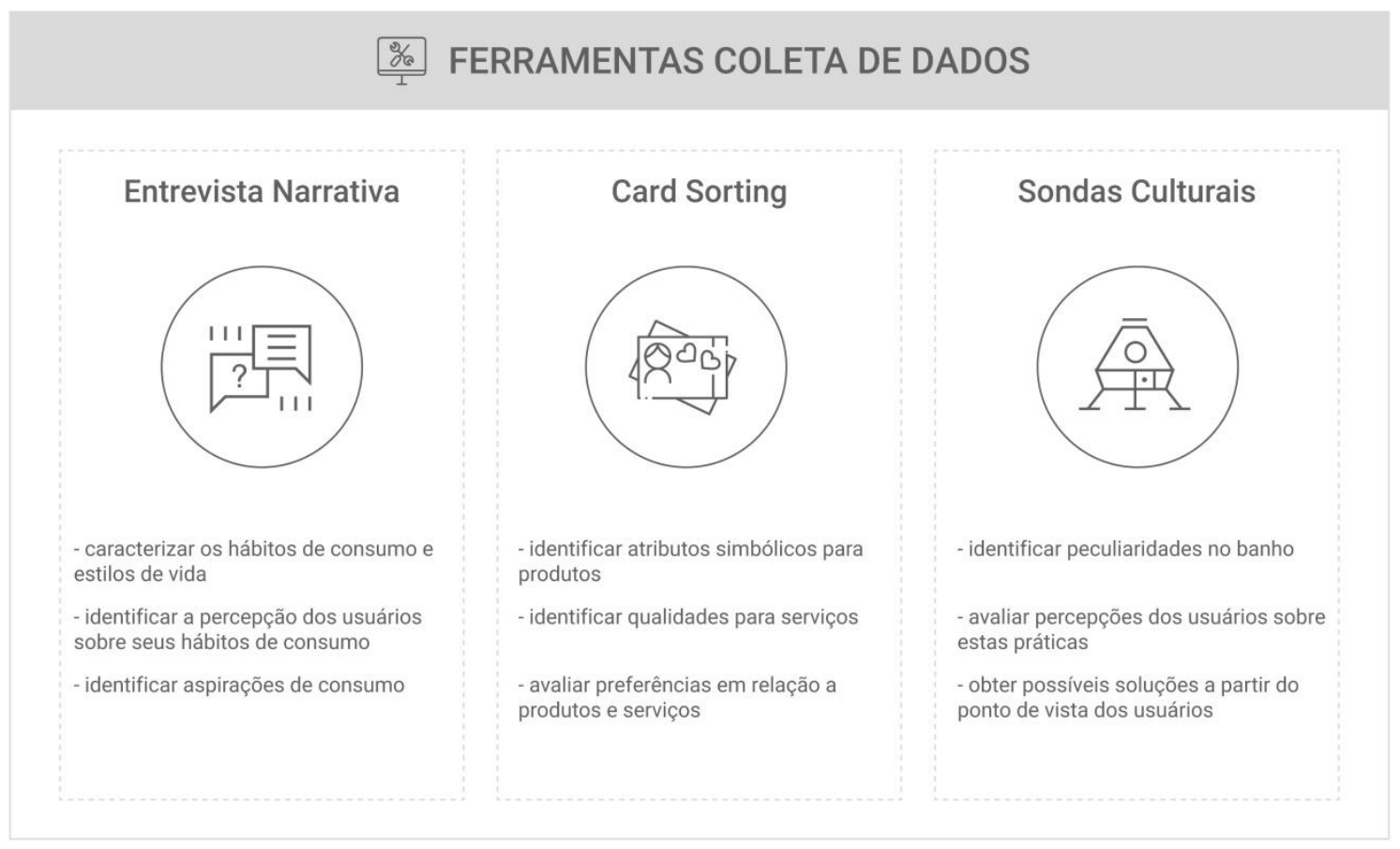

Figura 01: Ferramentas de coleta de dados em campo.

O kit de Sondas Culturais foi desenvolvido de acordo com os preceitos propostos na dissertação de Daros (2013). Em nossa pesquisa as ferramentas utilizadas foram customizadas e nomeadas como: "lâmpada das ideias" e "confessionário" (Figura 02).

Diferente das ferramentas anteriores, as sondas culturais desenvolvidas permitem a participação de toda a família, contribuindo para o mapeamento dos hábitos de forma mais abrangente. 


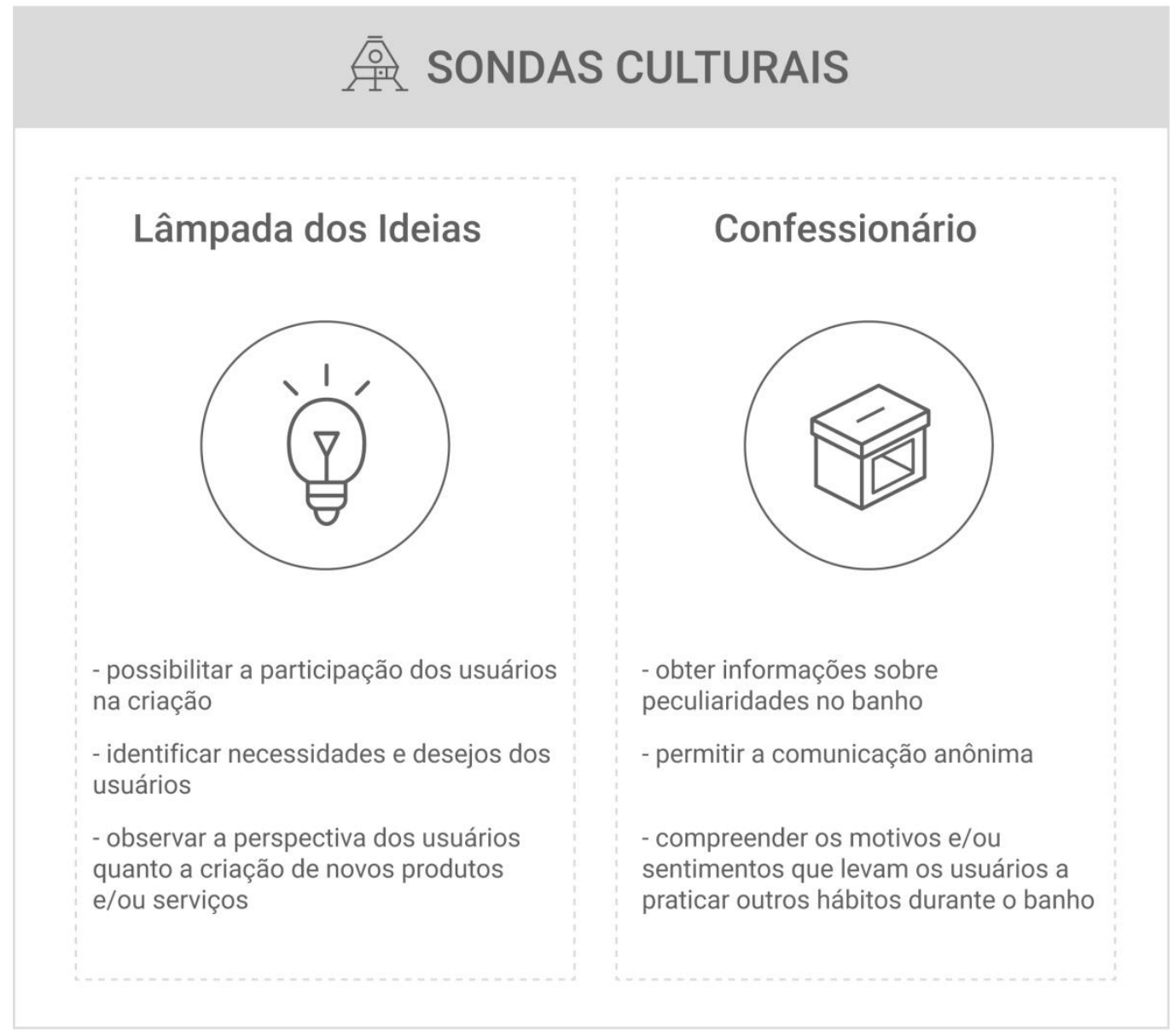

Figura 02: Sondas Culturais.

A lâmpada das ideias (Figura 03) é uma ferramenta desenvolvida para coletar ideias dos próprios usuários em relação à melhoria da atividade de tomar banho. Estas sugestões podem abranger produtos ou serviços, necessidades, desejos, conforme a vontade dos usuários. Deixamos a lâmpada das ideias por aproximadamente uma semana no banheiro dos participantes, junto com algumas sugestões sobre temas que poderiam ser abordados nas soluções (tecnologia, aplicativos, produtos para o banho, acessórios para o banheiro, monitoramento, etc.).

As sugestões, porém, não tinham caráter obrigatório, deixando o usuário livre para acrescentar suas contribuições intuitivamente. Junto com o kit de sondas culturais, deixamos canetas e blocos para anotações para que os usuários pudessem anotar e depositar as ideias dentro da lâmpada. 


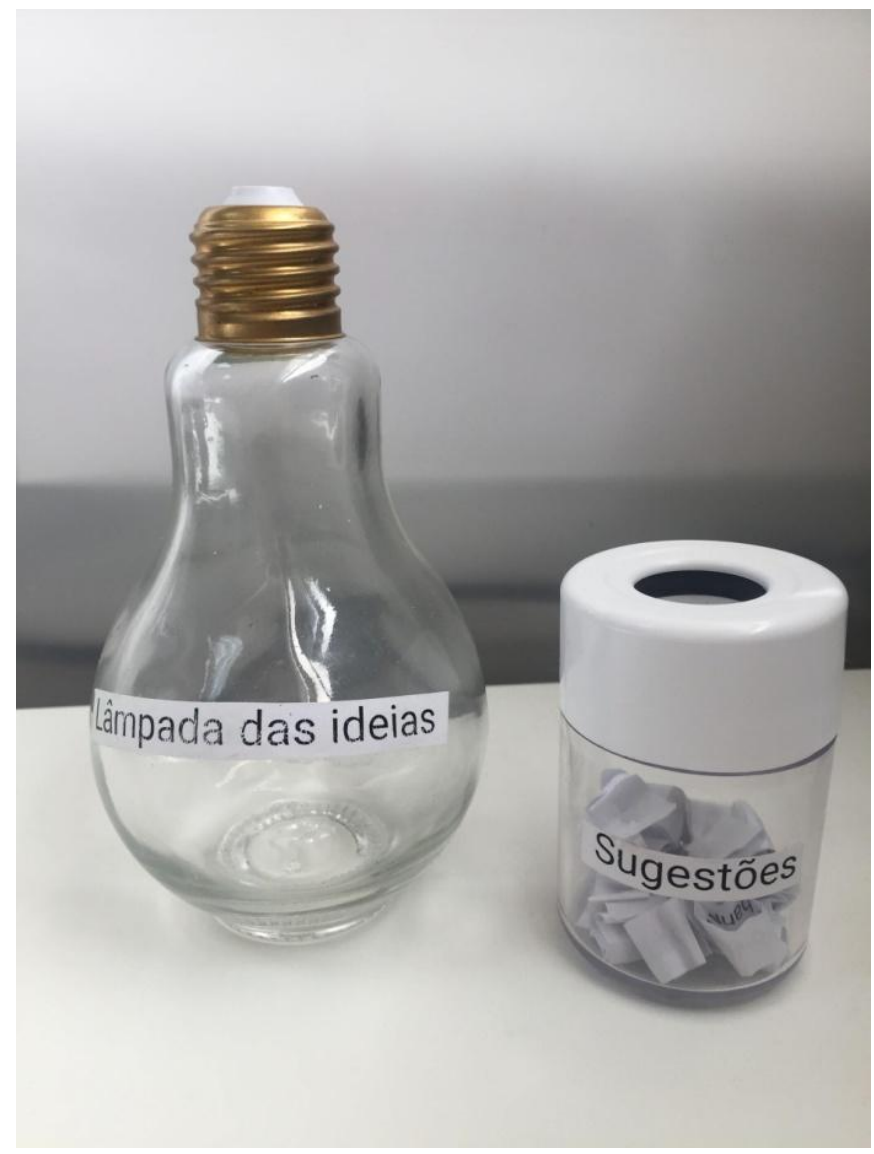

Figura 03: Lâmpada das ideias.

O confessionário (Figura 04) é uma sonda cultural desenvolvida para compreender atividades realizadas durante o banho que seriam de difícil admissão por parte dos usuários nas entrevistas.

Junto com a lâmpada das ideias, deixamos o confessionário no banheiro das famílias por aproximadamente uma semana, com bloco de anotações e caneta disponíveis aos participantes. Os usuários foram orientados a depositar no confessionário atividades que não tem relação com a limpeza corporal ou outras informações sobre o banho que pudessem ser relevantes para a pesquisa. O recipiente do confessionário é completamente fechado de modo que outros membros da família não poderiam acessar as informações ali depositadas.

Pedimos aos usuários para que depositassem as informações diariamente, logo após a saída do banho, de modo que a sonda cultural fosse mais eficiente e coletasse as informações de modo instantâneo. É importante destacar que não mencionamos em nenhum momento que as peculiaridades depositadas no confessionário deveriam ter relação com o desperdício de água e/ou energia. 


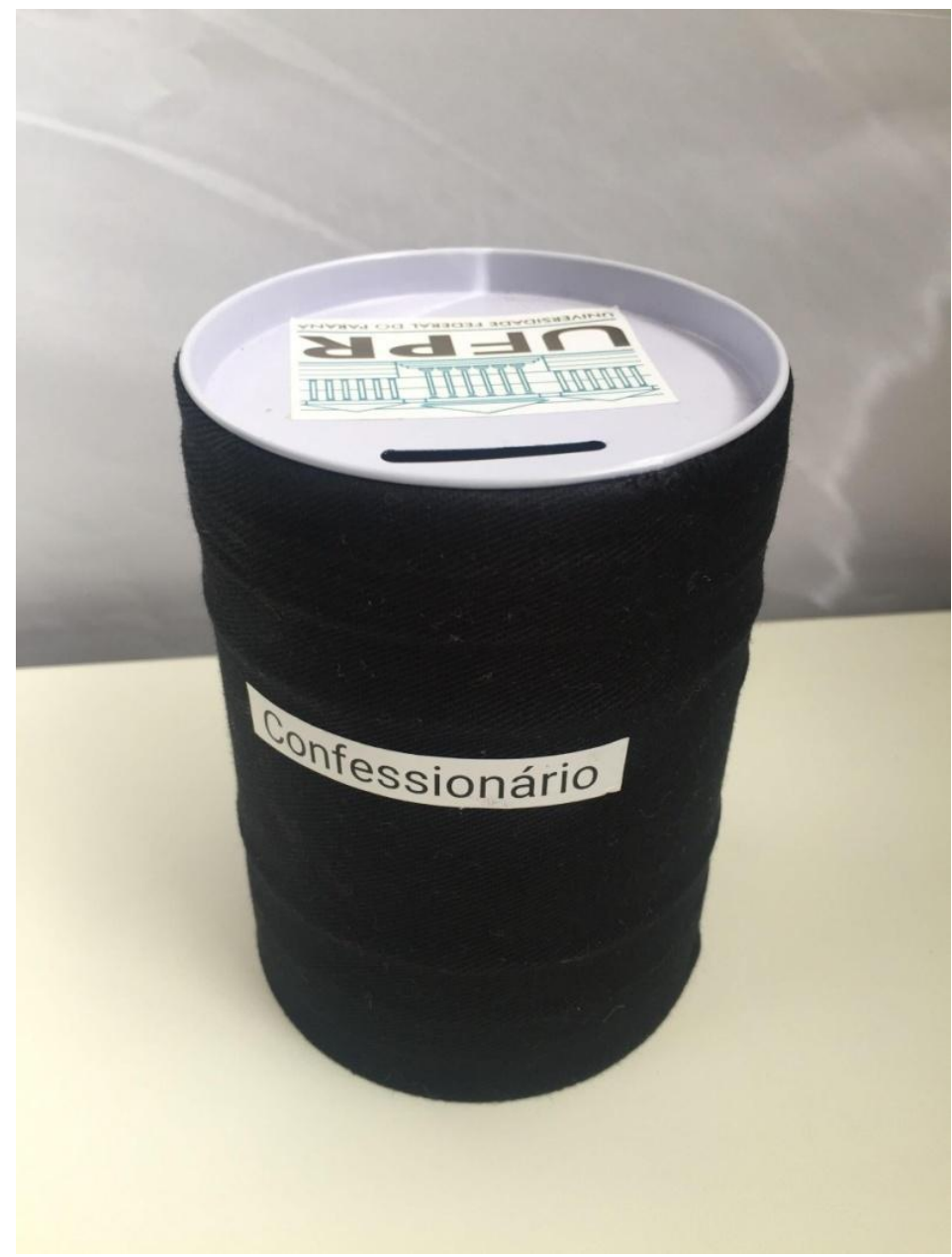

Figura 04: Confessionário.

As sondas auxiliaram na caracterização do banho e de outros hábitos que vão além da limpeza corporal que são realizados neste momento e que muitas vezes são os principais responsáveis pelo dispêndio de tempo no banho. Além disso, as sondas culturais também possibilitaram a coleta de informações mais subjetivas sobre o que momento do banho representa para os usuários que participaram da pesquisa. Estas informações ajudam a guiar o desenvolvimento de novos artefatos de forma mais empática e com foco na perspectiva dos próprios usuários.

\section{Sobre a definição do perfil das entrevistadas}

Todas as participantes da pesquisa vivem na cidade de Curitiba e região metropolitana. Definiu-se que para participar da pesquisa elas deveriam residir em HIS (habitações de interesse social) e possuir baixa renda. Também definimos que as principais interlocutoras da pesquisa seriam mulheres.

Em grande parte dos lares, por questões culturais, as atividades domésticas ainda costumam ter um peso maior sobre as mulheres. As exigências sobre elas são maiores, pois além de 
trabalhar fora e cumprir horários da mesma forma que os homens, ainda é esperado que a educação dos filhos e a administração do lar também sejam realizadas por elas (BORSA, FEIL, 2008). Principalmente em contextos de baixa renda, é possível observar este acumulo de funções por parte das mulheres. Assim, elas acabam por ser responsáveis também pela educação no que diz respeito a atividades domésticas cotidianas, como o banho. Em muitos casos, também são elas que controlam o consumo de água e energia não apenas de si próprias, mas também de outros membros da família.

Devido ao seu papel dentro dos lares, as mulheres podem falar sobre seus hábitos de banho e também sobre os hábitos de outros membros da família. Na aplicação das sondas culturais, os demais membros da família também foram convidados a se envolver e participar. As interlocutoras principais continuaram sendo, no entanto, as mulheres. Definimos que todas as participantes deveriam ter entre 25 e 60 anos, com renda familiar de no máximo três salários mínimos, viver em uma HIS e possuir um grupo familiar de no mínimo três pessoas.

\section{Sobre as participantes da pesquisa}

Para a realização da pesquisa de campo estabelecemos contato direto com moradores de Habitação de Interesse Social. Também foi realizado um esforço de contato junto a instituições associadas à implementação de moradias e sistemas para a população de baixa renda. Os esforços que mostraram maior efetividade foram aqueles onde estabelecemos contato direto com moradores que atendiam o perfil da pesquisa e também líderes comunitários. Assim, a pesquisa foi aplicada com seis usuárias, todas correspondentes aos perfis mencionados.

A primeira participante reside na região metropolitana de Curitiba, tem 47 anos de idade, vive em uma casa de alvenaria sem pintura, com o piso de cimento cru, que possui dois quartos e um banheiro, sendo este compartilhado pelos três moradores da casa. A interlocutora, assim como seu marido, possui emprego formal, mas a renda total da família ainda é menor que três salários mínimos mensais. A família possui microcomputador e aparelhos de smartphone, mas não possui internet banda larga. Como é uma funcionária terceirizada da universidade, a acompanhamos até a sua casa após seu expediente de trabalho. Caminhamos juntas até o ponto de ônibus enquanto conversávamos sobre nossas famílias, o que ajudou no estabelecimento de um vínculo de confiança que possibilitou que a participante se sentisse confortável para receber alguém que ela não conhecia muito bem em seu lar. Demoramos pouco mais de uma hora no ônibus e logo que descemos entramos em uma rua ainda sem asfalto. Antes de chegar à casa da participante paramos em uma padaria para comprar pães e bolos para um lanche antes da pesquisa. Ao chegar na casa fomos recebidas pela filha da participante, uma adolescente de 14 anos, que já estava informada a respeito da pesquisa e tinha muita vontade e motivação para contribuir. Logo após o café, seguimos com o protocolo de coleta de informações, primeiro com uma entrevista narrativa onde ambas contribuíram, depois com o card sorting e por fim encontramos um local no banheiro para fixar as sondas culturais, que permaneceram na residência por cerca de uma semana. 
A segunda entrevistada, também residente da região metropolitana de Curitiba é uma líder comunitária que já tinha participado e contribuído com outras pesquisas do nosso laboratório anteriormente. Com 43 anos de idade, ensino fundamental incompleto ela é proprietária de um pequeno comércio na garagem da sua residência, enquanto o marido é trabalhador autônomo e presta serviços de infraestrutura pública para a prefeitura. A interlocutora vive com o marido e com o neto de oito anos de idade em uma casa de alvenaria de muro baixo, onde circulam sempre muitas pessoas que frequentam o comércio da casa. A renda da família geralmente alcança os três salários mínimos. Esta participante possui aparelhos smartphones e internet banda larga, que compartilha com as filhas que moram na vizinhança. A visita aconteceu em um sábado, quando ela disponibilizou um tempo para nos receber. Assim como a participante anterior, compartilhamos uma refeição enquanto trocamos informações sobre alguns eventos que aconteceriam na associação de moradores em datas próximas. Após a pesquisa, a interlocutora indicou outras participantes para, assim como ela, contribuir espontaneamente com a pesquisa.

$\mathrm{Na}$ entrevista seguinte a usuária tinha 49 anos de idade, ensino fundamental incompleto e, no momento em que foi realizada a entrevista, estava desempregada. Ela é casada e vive com o marido, uma filha e três netos em um pequeno apartamento da COHAPAR (Companhia de Habitação do Paraná) na periferia de Curitiba. A renda média da família fica entre dois e três salários mínimos. Ela possui aparelho smartphone e internet banda larga. Assim que chegamos fomos recebidos por dois dos netos da participante, que acompanharam toda a entrevista entre brincadeiras e interrupções com pedidos de atenção. Tivemos que negociar com as crianças o tempo da avó. Essa situação se repetiu na maioria das residências que visitamos, com crianças estavam presentes em todas as casas demandando tempo e cuidados dessas mulheres. Nesta visita foi possível perceber o desgaste da avó que, como responsável pelo cuidado dos netos, acabou levando mais tempo que as outras participantes para conseguir responder e completar as sondas culturais (cerca de um mês).

A quarta entrevista foi com uma participante de 24 anos de idade, ensino fundamental completo, que vive na região metropolitana de Curitiba. A usuária se dedica aos afazeres domésticos, enquanto seu marido possui emprego formal. Ela possui dois filhos, mas apenas um deles vive com a família, pois a renda da família é menor que dois salários mínimos e ela diz não ter condições financeiras para cuidar dos dois. A participante e seu marido possuem aparelhos smartphone, mas não possuem internet banda larga. A casa é simples e sem pintura, com o piso de cimento coberto por tapetes e possui apenas três cômodos: cozinha-sala, quarto e banheiro. Essa participante também conseguiu completar as tarefas das sondas culturais em uma semana.

A quinta interlocutora entrevistada possuía 30 anos de idade e ensino fundamental incompleto no momento da entrevista. Esta usuária também se dedica às atividades domésticas e a tomar conta dos três filhos pequenos. O marido é autônomo e a renda da família também é menor que dois salários mínimos. O casal possui aparelho smartphone, mas não possuem internet banda larga. Esta casa estava localizada no final de uma rua não asfaltada. A casa, apesar de grande, não possuía acabamentos ou pintura. Iniciamos a entrevista na cozinha, onde éramos constantemente interrompidos pelas crianças e também foi necessário negociar com elas 
a atenção da mãe. Esta família já tinha participado de outras pesquisas do nosso laboratório e o marido da interlocutora gostava muito de dar ideias e contribuições. Embora ele não estivesse presente no momento da entrevista, procurou contribuir com as sondas culturais, principalmente com a lâmpada das ideias.

Por fim, na última entrevista a interlocutora tinha 54 anos de idade e ensino fundamental incompleto, era divorciada e morava com um dos filhos e cinco netos, sendo que a renda familiar ficava entre dois e três salários mínimos. Ela possuía aparelho celular convencional e não havia internet banda larga na residência. Esta usuária faz parte de outra associação de moradores, que foram beneficiados com a habitação social, sendo que antes residiam em áreas de risco de desmoronamento, à beira de um rio na periferia de Curitiba. Acompanhamos esta usuária da associação de moradores até a sua casa também via transporte público, onde foi possível estabelecer um contato mais íntimo com ela. Esta participante também demorou para devolver as sondas culturais pois, segundo ela, o cuidado com os netos pequenos the exigia muito de seu tempo livre e dificultava a realização de atividades que estavam fora da rotina familiar.

\section{Análise dos resultados}

A análise das sondas culturais foi feita de forma individual, inicialmente independente das outras ferramentas de coleta de dados, devido a particularidade das informações. A aplicação das sondas culturais possibilitou a compreensão de hábitos, anseios, desejos e reflexões que não foram comentados pelos usuários nas entrevistas ou no card sorting.

Práticas associadas ao hábito do banho como cantar, escovar os cabelos, ensaiar apresentações e brincar, foram integrados na caracterização do banho por meio das sondas culturais. Anseios e preocupações com o consumo de água e energia e a duração banho também foram identificados com a ferramenta, além de manifestações de sentimentos contidos, como chorar e gritar. Estas informações foram analisadas e contribuíram para a identificação dos requisitos de projetos que envolvem o hábito do banho.

\section{Análise do Confessionário}

Como exemplo das informações obtidas com a sonda cultural "confessionário", temos o relato de dois casos: entrevista 01 e entrevista 04.

O "confessionário" permaneceu na casa da participante por sete dias e obteve nove respostas (Figura 05). É possível identificar que os usuários utilizam tecnologias para entretenimento durante o banho, como assistir televisão e escutar músicas. A resposta "Brinco com meus brinquedos no chuveiro" mostra que as crianças também contribuíram comentando sobre seus hábitos associados ao banho. Criar soluções sensoriais e lúdicas pode ser um caminho interessante para conscientizar as crianças e envolvê-las no processo de transição para hábitos de utilização dos recursos cada vez mais conscientes. 


\begin{tabular}{|c|c|}
\hline (8) CONFESSIONÁRIO EF01 & 湿 REQUISITOS \\
\hline $\begin{array}{l}\text { 1. "Gosto de tomar banho assistindo TV" } \\
\text { 3. "Gosto de tomar banho na água quente para relaxar' } \\
\text { 5. "Meu corpo fica com menos dor" } \\
\text { 6. "Brinco com brinquedos no chuveiro" } \\
\text { 7. "Banho antes de dormir para relaxar o corpo e a mente" } \\
\text { 8. "Dou banho no meu filho primeiro e depois eu tomo banho" } \\
\text { 9. "Gosto de ligar música e estar sozinha em casa pra tomar } \\
\text { um banho sossegada" }\end{array}$ & 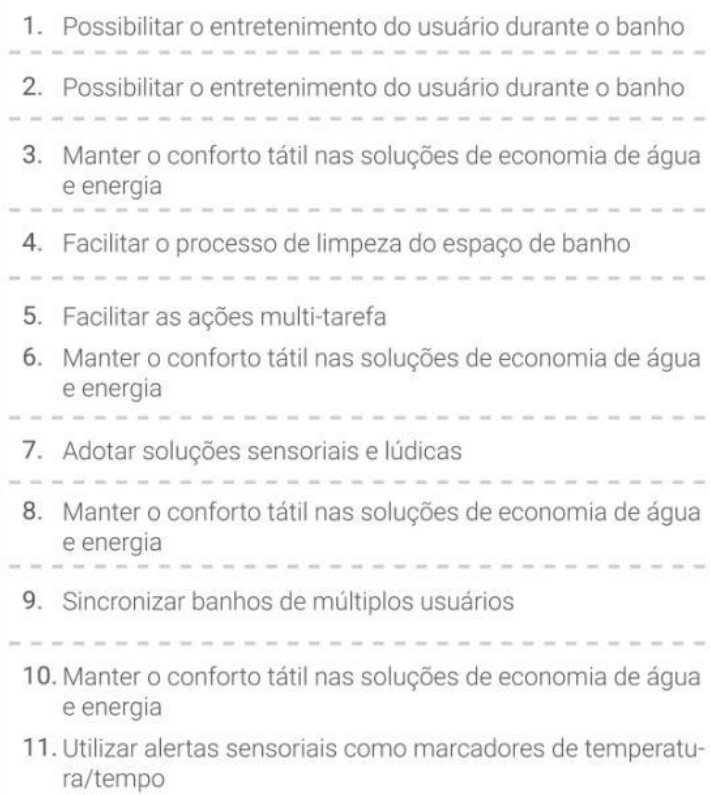 \\
\hline
\end{tabular}

Figura 05: Dados e Requisitos Confessionário 01.

Durante a entrevista narrativa esta usuária já havia mencionado o seu hábito de limpar o ambiente de chuveiro antes do banho. Facilitar esta prática pensando em meios de uso racional da água e da energia também durante a limpeza do ambiente pode contribuir com a gestão do consumo.

O alívio de dores musculares e o relaxamento corporal também são atribuídos ao banho, como é possível observar nas respostas 3, 5 e 9. O requisito "Manter o conforto nas soluções de economia de água e energia" diz respeito à aceitação dos usuários no que tange a essas possíveis soluções, sejam elas quais forem. Como além da limpeza corporal o relaxamento é uma das unidades de satisfação do banho, entendemos que é necessário mantê-la, porém levando em consideração a conscientização no uso da água e energia. Para auxiliar o usuário a controlar o tempo e o consumo no banho, utilizar alertas sensoriais pode contribuir, sem que seja necessário deixar de lado o conforto.

Em relação a entrevista 04 a sonda cultural "confessionário" também permaneceu na casa da participante por uma semana e foram obtidas com a ferramenta sete respostas. Como pode ser observado na Figura 06, as atividades envolvendo entretenimento também estão presentes no banho de acordo com as respostas 1 e 2 . Assim como na entrevista anterior, também foi mencionada a limpeza do banheiro, porém neste caso a limpeza é realizada durante o banho. 


\begin{tabular}{|c|c|}
\hline CONFESSIONÁRIO EF04 & $\Rightarrow$ REQUISITOS \\
\hline $\begin{array}{l}\text { 1. "Entrei no banho ouvindo música } \\
\text { 2. "Eu gosto de ver vídeos no banho" } \\
\text { 3. "Tenho mania de limpar o banheiro no banho' } \\
\text { 6. "Banho onde penso na vida porque é um lugar calmo" } \\
\text { "Banho onde planejo o que vou fazer no dia seguinte" }\end{array}$ & $\begin{array}{l}\text { 1. Possibilitar o entretenimento do usuário durante o banho } \\
\text { 3. Facilitar o processo de limpeza do espaço de banho } \\
\text { 4. Utilizar alertas sensoriais como marcadores de temperatu- } \\
\text { ra/tempo } \\
\text { 6. Manter o conforto tátil nas soluções de economia de água } \\
\text { 7. Utilizar alertas sensoriais como marcadores de temperatu- } \\
\text { ra/tempo } \\
\text { 8. Manter o conforto tátil nas soluções de economia de água } \\
\text { e energia } \\
\text { 7. Utilizar alertas sensoriais como marcadores de temperatu- } \\
\text { ra/tempo } \\
\text { 8. Manter o conforto tátil nas soluções de economia de água } \\
\text { e energia } \\
\text { 9. Manter o espaço do banho acusticamente isolado }\end{array}$ \\
\hline
\end{tabular}

Figura 06: Dados e Requisitos Confessionário 02.

Outra resposta que apareceu no Confessionário foi: "Ler os frascos dos produtos no banho". As respostas 5, 6 e 7 também mostram uma tendência à distração. Além disto, o comentário 7 "Banho é onde sempre choro quando tô triste" também mostra relação com um momento de intimidade e privacidade, no qual é possível pensar e voltar-se para suas questões pessoais, sem a presença dos outros membros da família. Pensando nisto, o requisito 9 foi acrescentado: "Manter o espaço do banho acusticamente isolado", como forma de preservar a privacidade das pessoas neste momento. Porém, o uso de alertas sensoriais de tempo também é importante, para auxiliar os usuários a fazer uma gestão do seu tempo no banho de forma mais consciente.

\section{Análise da Lâmpada das Ideias}

Os dados obtidos com a lâmpada das ideias foram analisados de forma semelhante ao confessionário. Estas informações, porém, tinham um caráter mais cocriativo, sendo que os participantes depositavam na lâmpada seus próprios insights para produtos e serviços que pudessem de alguma forma, melhorar a prática do banho. Para exemplificar a análise destes dados, apresentamos as informações coletadas nas entrevistas 01 e 03 .

A sonda cultural "Lâmpada das Ideias" permaneceu na casa dos primeiros entrevistados por sete dias e obteve doze contribuições. Pode ser visualizado na Figura 07 como as ideias dos usuários permitiram realizar inferências acerca das tensões associadas aos hábitos, sendo convertidas em requisitos de projeto. A ideia "um projeto para reutilizar a água" confirma que os usuários estão dispostos a armazenar e reutilizar a água do banho se possuirem acessórios que permitam tal prática. 


\begin{tabular}{|c|c|}
\hline f) IDEAIS DO USUÁRIO & E REQUISITOS \\
\hline 1. "Acredito que criando um projeto para reutilizar a água" & $\begin{array}{l}\text { 1. Possibilitar armazenamento da água do banho } \\
\text { 2. Possibilitar o armazenamento e reúso da água do banho }\end{array}$ \\
\hline $\begin{array}{l}\text { 2. "Com um aplicativo, assim calculo meu tempo no banho e a } \\
\text { quantidade." }\end{array}$ & $\begin{array}{l}\text { 3. Possibilitar o controle do consumo de água e energia em tempo real } \\
\text { 4. Permitir o controle do tempo de banho pelo próprio usuário }\end{array}$ \\
\hline $\begin{array}{l}\text { 3. "Tomar banhos mais breves, já pensando em economia do } \\
\text { futuro." }\end{array}$ & 5. Permitir o controle do tempo de banho pelo próprio usuário \\
\hline 4. "Ligar um ar-condicionado no banho." & $\begin{array}{l}\text { 6. Possibilitar a climatização do banheiro de acordo com a temperatura } \\
\text { ambiente }\end{array}$ \\
\hline 5. "Quando a água está mais quente a limpeza é melhor." & 7. Possibilitar pré-aquecimento da água dá água do banho \\
\hline 6. "Chuveiro com música, luzes e bem grande!" & $\begin{array}{l}\text { 8. Ampliar o tamanho do chuveiro elétrico sem aumentar o consumo } \\
\text { 9. Adotar soluções sensoriais e lúdicas }\end{array}$ \\
\hline 7. "Um banheiro confortável e grande!" & $\begin{array}{l}\text { 10. Ampliar a percepção de espaço do banheiro } \\
\text { 11. Melhorar a distribuição dos componentes no banheiro }\end{array}$ \\
\hline 8. "Quando está frio estraga a minha experiência no banho" & $\begin{array}{l}\text { 12. Possibilitar a climatização do banheiro de acordo com a temperatura } \\
\text { ambiente } \\
\text { 13. Possibilitar pré-aquecimento da água dá água do banho }\end{array}$ \\
\hline $\begin{array}{l}\text { 9. "Se faltasse sabonete e xampu eu iria me lavar com sabão } \\
\text { de pedra" }\end{array}$ & 14. Ampliar a sensação de limpeza corporal pós-banho. \\
\hline 10."Não pode faltar no banho a água e a sabonete" & 15. Ampliar a sensação de limpeza corporal pós-banho. \\
\hline 11."Devemos nos higienizar todos os dias" & 16. Instrumentalizar o processo de ensino de hábitos \\
\hline $\begin{array}{l}\text { 12."No futuro os banhos serão mais avançados na tecnologia e } \\
\text { mais legais" }\end{array}$ & 17. Promover novas experiências ao usuário no momento do banho \\
\hline
\end{tabular}

Figura 07: Dados e Requisitos Lâmpada das ideias 01.

Fica evidente nestes resultados a preocupação dos moradores em evitar o desperdício e controlar o tempo e o consumo de água e energia no banho. Estas ideias e preocupações foram associadas aos requisitos referentes a possibilitar o controle do consumo pelo usuário e permitir o controle do tempo no banho.

A questão do aquecimento do banheiro em dias frios e a associação da água quente com a limpeza mais efetiva foram associadas aos requisitos que abordam a temperatura da água e a climatização do banheiro. Entende-se que "possibilitar a climatização do banheiro de acordo com a temperatura ambiente", seja de calor ou frio, pode contribuir para que o usuário tenha um maior controle sobre o seu banho, visto que muitas vezes acaba-se demorando mais no banho quando está frio. Já o requisito relacionado a "Possibilitar o pré-aquecimento da água do banho" está relacionado com a demora relatada pelos usuários para o aquecimento da água depois que o chuveiro é ligado. Esta demora, além de trazer desconforto para o usuário também implica em desperdício de água.

Como pode ser visto nas ideias 6 e 7, o banho ideal é associado ao conforto e relaxamento, sendo que os usuários associam outros fatores como música, luzes e amplo espaço à mesma unidade de satisfação. Assim, identificamos como requisitos "Ampliar a percepção de espaço do banheiro", "Adotar soluções sensoriais e lúdicas", "Melhorar a distribuição dos componentes no 
banheiro" e "Ampliar o tamanho do chuveiro elétrico sem aumentar o consumo". A percepção de tamanho do chuveiro é associada com a sua potência, sendo que quanto maior é o chuveiro, maior é a percepção de qualidade do produto.

Os produtos de higiene para o banho são considerados fundamentais pelo usuário como pode ser visto nas ideias 9 e 10. Desta forma, criou-se o requisito "Ampliar a sensação de limpeza corporal pós-banho", de forma que com produtos mais efetivos em promover a sensação de limpeza os usuários sintam menos necessidade de tomar banho, especialmente no verão.

Finalmente, é comentado na lâmpada que "Devemos nos Higienizar todos os dias". Assim, criar produtos e serviços que possam contribuir para o ensino dos hábitos de higiene, associados ao uso racional da água e energia, pode ajudar a tornar os usuários mais conscientes sobre o seu consumo.

Na terceira entrevista, a "Lâmpada das Ideias" permaneceu por quase um mês e foram coletadas onze ideias que contribuíram para a geração de requisitos para o projeto (Figura 08). Muitas das informações provenientes da lâmpada das ideias na entrevista 03 têm o foco no relaxamento e alívio do stress cotidiano. A usuária volta a mencionar soluções que possam atender as crianças em seus banhos, além de mencionar os produtos que utiliza para a limpeza corporal. Esta entrevista confirma o que foi dito em ferramentas anteriores e reforça os requisitos já identificados.

\begin{tabular}{|c|c|}
\hline Q- IDEAIS DO USUÁRIO & E REQUISITOS \\
\hline 1. "Um tapete de banho massageador" & 1. Manter o conforto tátil nas soluçōes de economia de água e energia \\
\hline 2. "Criar um sabonete bem anti stress" & 2. Manter o conforto tátil nas soluções de economia de água e energia \\
\hline 3. "Uma esponja bem relaxante seria uma boa?" & 3. Manter o conforto tátil nas soluções de economia de água e energia \\
\hline 4. "Um chuveiro anti stress seria uma boa" & 4. Manter o conforto tátil nas soluções de economia de água e energia \\
\hline $\begin{array}{l}\text { 5. "xampu, sabonete e condicionador são meus produtos de } \\
\text { limpeza" }\end{array}$ & $\begin{array}{l}\text { 5. Facilitar o acesso a produtos para o banho com menor impacto } \\
\text { ambiental }\end{array}$ \\
\hline 6. "Ao falar uma frase o chuveiro abra e feche sozinho" & 6. Automatizar os componentes dos sistemas \\
\hline 7. "Um chuveiro bem grande, que tenha uma ducha bem grande" & 7. Ampliar o tamanho do chuveiro elétrico sem aumentar o consumo \\
\hline 8. "Um chuveiro de desça água aromatizada" & $\begin{array}{l}\text { 8. Manter o conforto tátil nas soluções de economia de água e energia } \\
\text { 9. Adotar soluções sensoriais e lúdicas }\end{array}$ \\
\hline 9. "Um chuveiro infantil pras crianças" & 10. Adotar soluções sensoriais e lúdicas \\
\hline $\begin{array}{l}\text { 10. "Se tivesse espaço guardaria água para lavar calçados e } \\
\text { roupas" }\end{array}$ & $\begin{array}{l}\text { 11. Integrar produtos e serviços para situaçōes de falta de água } \\
\text { 12. Possibilitar armazenamento da água do banho } \\
\text { 13. Permitir a reutilização das águas cinzas }\end{array}$ \\
\hline 11. "Lavar por exemplo roupa e chinelo no banho é desperdício" & $\begin{array}{l}\text { 14. Facilitar as ações multi-tarefa } \\
\text { 15. Possibilitar o controle do consumo de água e energia em tempo real }\end{array}$ \\
\hline
\end{tabular}

Figura 08: Dados e Requisitos Lâmpada das ideias 02.

$\mathrm{Na}$ terceira entrevista também é possível identificar a disposição para armazenar e reutilizar a água do banho para limpeza, sendo apresentado, porém, o problema da restrição de espaço. A maioria das usuárias entrevistadas afirma que o seu banheiro é pequeno e se dizem insatisfeitas com o espaço. Para viabilizar estas soluções de armazenamento e reuso da água do banho é 
importante levar em consideração o tamanho destes banheiros. A usuária ainda afirma que considera lavar peças de roupa e chinelo no banho é um desperdício, mas não diz nada sobre a escovação dos dentes, hábito citado no confessionário. Isto mostra que os usuários estão conscientes do desperdício em relação a alguns comportamentos, mas não em outros.

\section{Considerações Finais}

Este trabalho discute a aplicação das sondas culturais na dissertação de Garcia (2019), autora principal deste artigo. A pesquisa já foi concluída e as sondas culturais foram ferramentas muito úteis para este tipo de situação, onde as relações com produtos e serviços acontecem em ambiente íntimo. Com a aplicação das sondas culturais, foi possível evidenciar a importância de investigar subjetividades que muitas vezes explicam porque determinados hábitos, como o banho, são tão difíceis de serem associados a um comportamento sustentável. Para muitas pessoas, o banho tem um significado que vai muito além da limpeza corporal, sendo relacionado a conforto, relaxamento, descanso e prazer. Neste caso, entendemos que estes outros benefícios não podem deixar de ser considerados quando buscamos projetar um banho "mais sustentável".

Com a aplicação das sondas culturais foi possível identificar questões que não ficaram tão evidentes na entrevista narrativa ou no card sorting utilizados na coleta de dados da pesquisa. As mulheres que participaram da pesquisa disseram que durante o banho podiam cuidar delas mesmas, ficar em silêncio e algumas vezes até mesmo chorar por algo que as entristeceu sem que outras pessoas vejam ou interfiram. Algumas relataram que esperam as crianças dormirem para poderem tomar banho sem serem interrompidas, pois é o único momento do dia em que não estão cuidando do marido ou dos filhos e podem assim pensar em si mesmas. Embora a pesquisa não tenha por objetivo discutir questões de gênero, as diferenças ficaram evidentes e influenciaram o hábito do banho, que para essas mulheres é um momento de descanso, fuga e isolamento das suas obrigações familiares e sociais. O hábito dos homens não foi investigado a fundo para que seja possível fazer um comparativo, já que foram as mulheres nossas principais interlocutoras. Porém, observamos uma oportunidade para pesquisas futuras, pois uma investigação mais profunda e focada em um viés de gênero pode revelar, por exemplo, diferenças no consumo entre homens e mulheres.

Em relação à utilização das sondas culturais, o foco mesmo deste artigo, percebemos que existe uma complexa rede de motivações que envolvem o hábito de tomar banho, tornando-o diferente de outros hábitos como a lavagem de roupas e louças ou limpeza da casa, por exemplo. Muitas destas especificidades, principalmente as mais subjetivas, não seriam captadas sem a utilização das sondas culturais e o engajamento das participantes.

É importante comentar que as sondas culturais desenvolvidas não foram amplamente aceitas por todas as participantes. Por mais que as ferramentas tenham sido elaboradas para serem de fácil utilização, não foi possível mensurar o que as participantes consideram fácil. Principalmente dentre as usuárias com maior faixa etária, verificamos certa relutância em participar da pesquisa, por acharem as sondas culturais complexas. Nestes casos, familiares 
mais jovens ajudavam as participantes no preenchimento das sondas, o que não é o ideal, considerando que o objetivo era captar aspectos relacionados à privacidade e intimidade. Algumas das participantes disseram ainda ter pouco tempo para se dedicar ao preenchimento das informações para as sondas culturais. Mesmo se tratando de anotações rápidas, era necessário refletir sobre os temas apresentados, principalmente na lâmpada das ideias, sendo que em algumas famílias as participantes não podiam contar com a colaboração de outros membros, que não se interessavam em discutir estas questões. Assim, algumas usuárias demoraram mais de uma semana (tempo previsto) para entregar as sondas, o que foi considerado trabalhoso por elas.

Percebemos que estas situações foram evitadas quando foi possível conversar com todos os integrantes das famílias e explicar a pesquisa antes da aplicação das sondas. Assim, a ferramenta poderia trazer melhores resultados se uma etapa de explicação e quebra gelo com toda a família fosse anteriormente prevista, para que todos os integrantes pudessem se engajar no preenchimento das informações e discutir as ideias entre si, não sobrecarregando apenas um dos usuários que já costuma estar sobrecarregado de tarefas domésticas. Neste sentido o perfil da família também é relevante, sendo que nas casas onde os cônjuges e filhos se interessavam em participar e contribuir com a pesquisa coletamos dados mais ricos e detalhados.

Assim, sugerimos que estas considerações sejam levadas em conta em pesquisas futuras e que o engajamento e a motivação sejam critérios para a seleção dos participantes. As sondas culturais são ferramentas muito úteis e valorosas, mas em contextos nos quais as pessoas possuem pouca instrução e disponibilidade de tempo podem não ter o seu potencial aproveitado plenamente.

\section{Referências}

BORSA, J. C.; FEIL C. F. O papel da mulher no contexto familiar: uma breve reflexão. O portal dos Psicólogos 185, 2008: 1-12.

CAVAllero, S. Tell the tools. Service design tools stories. 2017. Master's Degree in Product Service System Design. Design School of Politecnico di Milano, Milano, Italy.

DAROS, C. Design para a Sustentabilidade: oportunidades de inovação a partir dos hábitos de consumo na habitação de interesse social. 2013. 183 f. Dissertação (Mestrado em Design) - Programa de Pós-graduação em Design, Universidade Federal do Paraná, Curitiba.

GARCIA, A. M. Consumo sustentável e o hábito de tomar banho: metaconceitos de sistemas produto+serviço sustentáveis para habitações de interesse social. 2019. $248 \mathrm{f}$. Dissertação (Mestrado em Design) - Programa de Pós-graduação em Design, Universidade Federal do Paraná, Curitiba.

KJELDSKOV, J. et al. Using cultural probes to explore mediated intimacy. Australasian Journal of Information Systems 11.2, 2004.

MATTELMÄKI, T. Design probes. Aalto University, 2006.

MOURA, J. F. NACARATO, A. M. A ENTREVISTA NARRATIVA: dispositivo de produção e análise de dados sobre trajetórias de professoras. Cadernos de Pesquisa, v. 24, n. 1, p. 15-30, 2017. 
MUYLAERT, C. J. et al. Entrevistas narrativas: um importante recurso em pesquisa qualitativa. Revista da Escola de Enfermagem da USP, v. 48, n. spe2, p. 184-189, 2014.

PADOVANI, S. RIBEIRO, M. A. Card Sorting: adaptação da técnica para aplicação ao design de sistemas de informação não digitais. InfoDesign-Revista Brasileira de Design da Informação, v. 10, n. 3, p. 293-312, 2013.

O'GRADY, J. V. O'GRADY, K. A designer's research manual: succeed in design by knowing your clients and what they really need. Rockport Publishers, 2009.

SANDERS, E. B-N. STAPPERS P. J. Probes, toolkits and prototypes: three approaches to making in codesigning. CoDesign 10.1, 2014: 5-14.

SANTOS, A. dos. Design Science. In: (Ed.). Seleção do método de pesquisa: guia para pós-graduandos em design e áreas afins. Curitiba: Insight, 2018.

\section{Sobre os autores}

\section{Aline Müller Garcia}

Atua como UX Designer e Researcher no Lactec - Instituto de Tecnologia para o

Desenvolvimento. É doutoranda do PPGDesign da UFPR e mestre em Design também pelo PPGDesign da UFPR (2019). Possui graduação em Design com habilitação em Projeto de Produto pela Univille (2013).

eilan.muller@gmail.com

\section{Aguinaldo dos Santos}

É professor Associado I do Departamento de Design da Universidade Federal do Paraná. Possui doutorado em Gestão da Produção pela Salford University (1999) e Pós-doutorado em Design Sustentável pelo Politecnico di Milano (2009). É bolsista produtividade nível 2 do CNPq. É coordenador do Núcleo de Design \& Sustentabilidade da UFPR desde 2002.

asantos@ufpr.br 